\title{
Facebook y aprendizaje informal: un nuevo planteamiento metodológico en la enseñanza de lenguas
}

\section{Facebook and Informal learning: a new methodological approach in language teaching}

\author{
María Angélica Giordano Paredes ${ }^{1 *}$ \\ agiordano@flog.uned.es \\ Universidad Nacional de Educación a Distancia, España
}

\section{Resumen:}

Esta investigación surge de la inquietud de innovar el proceso de aprendizaje y enseñanza, específicamente de las lenguas extranjeras, adecuando los contenidos a los intereses de los discentes del siglo $\mathrm{XXI}$, para dar paso al uso colectivo de la información. Los objetivos principales se centran en la evaluación del aprendizaje informal: evaluar a través de estímulos y de dinámicas alternativas entre la autoevaluación y la coevaluación, a través del desarrollo y la puesta en práctica de competencias y estrategias facilitadoras del aprendizaje. Para la realización del proceso experimental, con alumnos de lengua italiana y de lengua española, se propusieron una serie de cursos piloto en los que se llevaron a cabo estudios cualitativos y cuantitativos relacionados con el aprendizaje a través de Facebook como red social y la distribución del trabajo en comunidades que adoptaron una dimensión constructiva del conocimiento, mediante el uso compartido de la información. Tal proceso hizo posible tanto la producción como el intercambio de conocimientos,

\begin{abstract}
:
This research paper is concerned with the implementation of innovation techniques in the process of learning and teaching foreign languages. Adapting contents to twenty-first century students' mentalities implies information has to be used collectively. Our main aims are the assessment of informal learning through stimuli and alternative dynamics which connect selfassessment and co-assessment, as well as developing and carrying out competences and strategies which facilitate learning. For the experimental process we worked with Italian and Spanish language students. In order to accomplish our goal, we delivered a series of collaborative courses in which qualitative and quantitative studies related to learning through Facebook as a social network were conducted. Besides, we distributed work among communities which adopted a constructive dimension of knowledge through the shared use of information. The process facilitated both the production and the exchange of knowledge based on the pragmatic and sociocultural nature of the contents, while
\end{abstract}

1 Dirección para correspondencia (Correspondence address):

María Angélica Giordano Paredes. Universidad Nacional de Educación a Distancia (UNED). Facultad de Filología. Departamento de Filologías Extranjeras y sus Lingüísticas. Área de Filología Italiana. Po Senda del Rey, 7. 28040 Madrid (España). 
Facebook y aprendizaje informal: un nuevo planteamiento metodológico en la enseñanza de lenguas

María Angélica Giordano Paredes

basándose en un comportamiento pragmático y sociocultural de los contenidos; pero teniendo en cuenta el desarrollo de las competencias básicas: saber ser y saber hacer. Los resultados fueron muy alentadores, aunque bastante controvertidos durante el proceso, considerando que los discentes llevan muchas generaciones en un sistema de aprendizaje individual; sin embargo las comunidades de aprendizaje los motivaron y al final se consiguió un resultado favorable, gracias a la puesta en práctica del aprendizaje informal.

\section{Palabras clave:}

Aprendizaje informal; redes sociales; facebook; evaluación; constructivismo; competencias; comunidades de aprendizaje. also taking into account the enhancement of basic competences such as know how to be and how to do. Results were very encouraging, although quite controversial during the collection process, due to the fact that students had been educated for generations in individualistic learning systems. However, learning communities strongly motivated them and, in the end, positive results were reported thanks to the implementation of informal learning.

\section{Key words:}

Informal learning; social networks; facebook; evaluation; constructivism; competences; learning communities.

\section{Résumé:}

Cette recherche naît du souci d'innover le processus d'apprentissage et d'enseignement, spécifiquement des langues étrangères, en adaptant les contenus aux intérêts des apprenants du XXIe siècle, pour faire place à l'utilisation collective de l'information. Les principaux objectifs sont axés sur l'évaluation de l'apprentissage informel : évaluer à travers des stimuli et des dynamiques alternatives entre l'auto-évaluation et la co-évaluation, par le développement et la mise en œuvre de compétences et de stratégies pour faciliter l'apprentissage. Pour la réalisation du processus expérimental, avec des apprenants de langue italienne et espagnole, on a proposé une série de cours pilotes dans lesquels on a réalisé des études qualitatives et quantitatives liées à l'apprentissage à travers Facebook comme réseau social et à la distribution du travail dans des communautés qui ont adopté une dimension constructive de la connaissance, à travers le partage d'informations. Ce processus a rendu possible la production et l'échange de connaissances, sur la base d'un comportement pragmatique et socioculturel des contenus, mais en tenant compte du développement de compétences de base : savoir être et savoir faire. Les résultats ont été très encourageants, bien qu'assez controversés au cours du processus, étant donné que les apprenants ont été dans un système d'apprentissage individuel pendant de nombreuses générations ; cependant, les communautés d'apprentissage les ont motivés et en fin de compte un résultat favorable a été atteint, grâce à la mise en œuvre de l'apprentissage informel.

\section{Mots clés:}

Apprentissage informel; réseaux sociaux; facebook; évaluation; constructivisme; compétences; communautés d'apprentissage.

Fecha de recepción: 01-11-2019

Fecha de aceptación: 09-03-2020 


\section{Introducción}

El proceso de enseñanza y aprendizaje necesita adaptarse a las nuevas generaciones y la mejor manera de hacerlo es acercándose a las herramientas motivadoras y facilitadoras que están al alcance de los protagonistas del proceso didáctico. De esta reflexión surgió la idea de utilizar los recursos que ofrece Facebook para crear las comunidades de aprendizaje y adaptarlas a las necesidades de los discentes, en la búsqueda constante de una nueva concepción de la enseñanza; pero con una dinámica diferente en la cual "el profesor (...) en lugar de suministrar conocimientos, participa en el proceso de generar conocimiento junto con el estudiante, de forma construida y compartida" (Álvarez, 2014, p. 93), para que éste ya no sea una entidad pasiva y receptiva, sino activa y protagonista. Es, sin lugar a dudas, un sistema mucho más sencillo que forma parte de la vida de los discentes y de su gestión cotidiana, permitiendo, además, el acercamiento del docente a sus intereses personales y académicos para gestionar mejor los contenidos y facilitar el desarrollo de las competencias necesarias para que el aprendizaje se convierta en una forma de vida y en un modo de ser y de hacer; es decir, en "una forma de pensar y de ver el mundo" (Álvarez, 2014, p. 94).

En esta experimentación, llevada a cabo con estudiantes de lengua italiana (LE), matriculados en el Curso de Acceso a la Universidad para mayores de 25 y 45 años, trabajadores en su mayoría y de intereses muy variados, y de lengua española (L2), de perfiles muy parecidos siendo la mayoría de ellos estudiantes universitarios de edades comprendidas entre los 18 y los 22 años y de proveniencia asiática, chinos, japoneses y coreanos, se propusieron varios cursos piloto en los que participaron más de trescientos alumnos de los niveles A1, A2, B1 y B2, durante tres años. Los objetivos didácticos se basaron en la puesta en práctica de las comunidades de aprendizaje, siguiendo los preceptos básicos del aprendizaje informal y del trabajo cooperativo, cuya intención era a) saber ser, en relación con los compañeros de la comunidad, para desarrollar un aprendizaje equitativo; b) alcanzar los conocimientos lingüísticos y culturales a través de la cooperación; c) organizar el propio proceso de aprendizaje de manera interactiva y en contacto con los demás miembros de la comunidad; d) ser autocríticos y orientar el aprendizaje en base a la autoevaluación y el intercambio en red de la coevaluación, como proceso final de la autocorrección y de la corrección compartida; 
Facebook y aprendizaje informal: un nuevo planteamiento metodológico en la enseñanza de lenguas

María Angélica Giordano Paredes

e) aprovechar los recursos tecnológicos para promover la interacción lingüística entre discentes y docentes mejorando, así, el aprendizaje; f) conseguir las competencias básicas, socioculturales y lingüísticas, necesarias para completar los requisitos básicos de cada nivel.

El desarrollo de las actividades y la distribución de los contenidos, así como la organización de los cursos en general, se llevó a cabo en Facebook. En dicha red social se crearon los grupos secretos en los que solo podían participar los miembros de la comunidad y un docente que era, en sí, un miembro más, con la función de organizar la información y guiar a los discentes durante el proceso didáctico.

En cuanto a la metodología utilizada se optó por un enfoque cualitativo y cuantitativo basado en la generación de datos relevantes, tanto gráficos como textuales, que verificaron el proceso de la experimentación y los resultados.

Aunque la finalidad de Facebook no haya sido, en sus orígenes, la didáctica, es innegable que su naturaleza comunitaria, en forma de red, permite la inserción de material didáctico y la creación de una dinámica que facilita el desarrollo de nuevas metodologías lingüísticas; considerando que ha cambiado la manera de percibir los conocimientos. Sin embargo, se han llevado a cabo pocos trabajos empíricos que demuestren, científicamente, la efectividad de Facebook como recurso de aprendizaje. Los dos más relevantes son El Proyecto Facebook y la pos universidad. Sistemas operativos sociales y entornos abiertos de aprendizaje, una investigación propuesta por Alejandro Priscitelli, Iván Adaime e Inés Binder, en la Universidad de Buenos Aires, en 2009 y El uso de Facebook como herramienta comunicativa en el aula de ELE de María del Pilar Concheiro Coello, un estudio Ilevado a cabo en la Universidad de Islandia en el que se puso en práctica el autoaprendizaje, en 2015. Ambas investigaciones coincidieron en la utilización de la filosofía constructivista y cognitiva (Garayzábal y Codesido, 2015) (Pepe, 1997 y Coinu, 2008), puesta en práctica a través del aprendizaje cooperativo y colaborativo y experimentado en las comunidades de Facebook; ya que "con la implementación de la formación a distancia, el aprendizaje se convierte en un proceso social y dinámico en el que el papel activo del usuario forma parte de las comunidades en las que prevalece el aprendizaje compartido" (Bartolotta, Giordano y Moreno, 2018, p. 71). En este caso es importante recalcar que "aprender a colaborar también se aprende" (Trujillo, Cáceres, Hinojo y Díaz, 2011, p. 101) y que tanto el 
docente como el discente son importantes en el proceso innovador. Por ello, el primero tiene que evaluar muy bien la didáctica que aplique y el segundo debe aportar sus capacidades y habilidades que permitan, del mismo modo, la innovación (Trujillo et al., 2011).

La transición del aprendizaje formal al informal está determinada por una serie de factores que gestionan tanto la didáctica como las herramientas y los espacios, abiertos, dinámicos e ilimitados, en los que se pueden constituir las comunidades de aprendizaje. En este ciberespacio cada uno de los componentes participa, activamente, desarrollando las diferentes actividades "socioculturales y pragmáticas basadas en los actos de habla" (Bartolotta et al., 2018, p. 73-74). Por esta razón se creó un espacio abierto, en el que se alojaron todos los recursos necesarios para el proceso didáctico, y que se denominó aula social, cuya finalidad consistió en distribuir los elementos básicos y las herramientas idóneas para que las comunidades de aprendizaje funcionaran en modo adecuado y cumplieran con los objetivos preestablecidos, definiendo el "aprendizaje como proceso social" (Trinchero, 2014), en un engranaje de conocimientos a disposición de toda la comunidad; ya que el procedimiento lingüístico está sujeto a las necesidades comunicativas de las personas involucradas en situaciones auténticas y específicas. Por lo tanto, en cuanto se refiere al aprendizaje de lenguas, lo que debe evaluarse y retroalimentarse son los resultados lingüísticos de los alumnos; es decir, textos orales y escritos, entre otras tareas o actividades (Wong, Chai y Aw, 2016).

En este sentido, la intención didáctica siguió un enfoque interactivo en un campo muy abierto en el que todos los participantes de las comunidades tuvieron la posibilidad de compartir, indiscriminadamente, toda la información y los conocimientos de los que disponían, conscientes de los cambios que se han producido en los estilos de aprendizaje y en la sociedad a partir del desarrollo de la era digital (Santalucia, 2015). Por otro lado, el acercamiento a Facebook permitió el contacto con la sociología pragmática que antepone la función colectiva de la información mediante la cual los individuos aprenden de los resultados, después de establecer un proceso de discusiones y de críticas en el interior de los grupos de debate. Como consecuencia, el concepto se convierte en bagaje cultural y en recurso social. Por lo tanto, sería oportuno señalar que las redes sociales, y Facebook en este caso, han transformado los modos de participación de las personas, creando un 
Facebook y aprendizaje informal: un nuevo planteamiento metodológico en la enseñanza de lenguas

María Angélica Giordano Paredes

enorme impacto social y contribuyendo a dinamizar el aprendizaje (Parra Castrillón, 2010).

En el siguiente estudio se ahondará en el proceso experimental, se especificará la metodología utilizada para llevar a cabo la investigación y se detallarán las actividades elegidas según el perfil del alumnado que participó en los cursos experimentales; así como un análisis generalizado de los resultados de la utilización de Facebook como herramienta de enseñanza y aprendizaje y cómo se planteó la evaluación y la corrección, terminando con líneas abiertas de planteamientos, encaminados a la colaboración de medios, individuos y herramientas.

\section{Proceso experimental}

Las comunidades de aprendizaje puestas en práctica en Facebook siguieron de cerca la normativa establecida en el Marco Común Europeo de Referencia para las Lenguas, con la finalidad de alcanzar los objetivos generales y específicos y adquirir las competencias lingüísticas y socioculturales correspondientes a los niveles A1, A2, B1 y B2, cuyos componentes oscilaban entre 12 y 15 alumnos. Los grupos pertenecientes a los niveles A1 y A2, encontraron, al principio, ciertas dificultades, sobre todo los estudiantes que no habían estado nunca en contacto directo con la cultura de la lengua de aprendizaje; pero las solventaron en poco tiempo, en cuanto empezaron a interactuar con los demás compañeros de la comunidad. Los estudiantes de niveles más altos (B1 y B2) respectivamente, encajaron mejor en la dinámica ya que muchos de ellos Ilevaban más tiempo estudiando la lengua (LE/L2) y algunos habían tenido la posibilidad de viajar y estar en contacto con los nativos de la lengua meta (italianos y españoles); por lo que tenían más dominio lingüístico. De este modo, se constituyeron varios grupos bastante heterogéneos pero, considerando que los discentes estaban integrados en una comunidad interactiva, facilitó mucho el proceso didáctico y el desnivel lingüístico ya que todos entraron en un engranaje compartido de aprendizaje recíproco. Otro factor importante que facilitó la adaptación fue la motivación debido a la admiración que todos sentían por la cultura meta (italiana y española); ya que la elección de la lengua de estudio fue más bien personal que profesional, y esto hizo que el proceso fuera mucho más agradable, divertido y eficaz. Además, gracias a la capacidad inte- 
ractiva de Facebook, los discentes consiguieron construir modelos de lengua en contextos reales, presentes en las muestras lingüísticas y en las pautas de autocorrección sintáctica, ortográfica, gramatical y pragmática.

En todo el proceso experimental se utilizaron las diferentes modalidades de aprendizaje, a distancia, presencial y semipresencial, cuya finalidad, además del aprendizaje, consistió en la consecución de una cierta madurez y la formación de la personalidad lingüística que los discentes conseguirían "con la adquisición de un amplio espíritu crítico a través de la argumentación de su trabajo y de los compañeros, en manera conjunta y cooperativa" (Bartolotta et al., 2018, p. 67-68).

\subsection{Herramientas y recursos}

La experimentación se llevó a cabo mediante el manejo de recursos integrados en Facebook como imágenes, páginas Web, vídeos de Youtube y de elaboración personal, documentos en formato Word y Pdf, principalmente. Además, se explotaron, de manera adecuada, las herramientas de las que dispone Facebook: chat, Gif, Sticker y la producción de vídeos en directo. Muchos estudiantes utilizaron la aplicación en formato móvil para facilitar la interacción ubicua y aprovechar el tiempo libre disponible para estudiar y entrar en contacto con los compañeros en la red o producir sus propios contenidos lingüísticos, gracias al mobile learning (aprendizaje a través de dispositivos móviles), que les permitía conectarse y trabajar en las comunidades de Facebook dondequiera que se encontraran y a cualquier hora del día; ya que la estructura interna de la red social en cuestión permite la creación de contenidos interactivos y facilita la "intertextualidad" que proviene de otros recursos externos y que enriquece tanto los contenidos como el modo de trabajar y de interactuar. La e-Collaboration, en este caso aplicada a Facebook, reúne una serie de características que facilitan el proceso didáctico con resultados más eficientes como accesibilidad y compartimiento de los contenidos, facilidad de comunicación, empleo de plataformas integradas, sincronía, asincronía y manipulación relevante de la información (Sancassani, Brambilla, Marenghi y Menon, 2011). 
Facebook y aprendizaje informal: un nuevo planteamiento metodológico en la enseñanza de lenguas

María Angélica Giordano Paredes

\subsection{Metodología}

La enseñanza de lenguas no se presenta en forma aislada sino que está sujeta a las circunstancias y a los ambientes que rodean el proceso didáctico; pero también al medio físico, a los cambios sociales y al entorno sociopragmático que construye y define la conducta de los individuos. Por esta razón se decidió utilizar el enfoque crítico ya que tanto discentes como docentes estaban estrechamente comprometidos con las mejoras del proceso didáctico; además de los métodos cuantitativo y cualitativo, basados en la observación, la inducción, la deducción, la comprobación y la evaluación. Para ello, se procedió a la planificación de las actividades niveladas, a la puesta en práctica de las mismas en las diferentes comunidades, a la observación de todo el proceso didáctico, mediante técnicas como notas de campo y diarios y, finalmente, a la reflexión sobre los resultados de aprendizaje mediante un seguimiento asiduo y pormenorizado de cada uno de los grupos. Todo esto sin dejar de lado las dificultades, debidas a los diferentes estilos de aprendizaje, y que se intentaron solventar gracias a la colaboración del grupo, además de las habilidades individuales que contribuyeron a sostener, en buena medida, todo el proceso didáctico que culminó con la evaluación como resultado de un proceso interno de coevaluación y autoevaluación, marcando así la diferencia entre las comunidades, localizando las carencias del proceso didáctico y comprobando la efectividad del aprendizaje informal.

Para determinar la eficacia de Facebook en la didáctica de lenguas extranjeras, fue necesario, además, apropiarse de técnicas como entrevistas realizadas tanto a los estudiantes participantes como a los docentes colaboradores sobre la experiencia y las necesidades del proceso didáctico. Se utilizaron también otras fuentes de datos como documentos y materiales digitales, imágenes, recortes, fotografías, gráficos, diagramas de redes sociales y cuestionarios para elaborar las actividades y diseñar las secuencias didácticas.

Así pues, el método cualitativo aportó los recursos necesarios para describir y descodificar a fondo la función didáctica y metodológica, a través de la disposición de materiales didácticos y documentación científica; mientras que el método cuantitativo estableció las medidas de las variables que intervinieron en el proceso de investigación, generalizando y explicando las relaciones de causa y efecto, en cuanto a la 
medición de los resultados en porcentajes a través de tablas y gráficos, de manera complementaria.

Esta tipología de investigación, por su propia naturaleza, resultó ser flexible, comunitaria, implicativa y ampliamente democrática, en la que se admitieron todos los cuestionamientos de los participantes y su colaboración en el análisis de los resultados. Tanto los alumnos como el docente se sumergieron en la experimentación, intentando agotar todas las vías de innovación tecnológica para avanzar y mejorar, en complicidad.

Se utilizó, además de las técnicas indicadas, la clase invertida, que permitió la preparación fuera del aula, tanto de manera autónoma como compartida. Sin embargo el desarrollo y puesta en práctica del aprendizaje electrónico está todavía en proceso, aunque los experimentos llevados a cabo estén demostrando que es tan efectivo como el convencional; y por esta razón no se puede afirmar que pueda sustituirlo, ni que el aula social se imponga a la tradicional. Lo que sí se puede demostrar es que el aprendizaje es, sobre todo, una actividad sociocognitiva (Zhang, Zhao, Zhou y Nunamaker, 2004).

Si bien es cierto que existe una gran controversia sobre el hecho de dar importancia al e-Learning en sustitución de la clase tradicional presencial, no hay que olvidar que queda mucho por recorrer y aprender en la enseñanza virtual. No obstante, muchos docentes, bastante comprometidos con los avances pedagógicos, intentan solventar los obstáculos con empeño y dedicación. Por esta razón esta experimentación lingüística forma parte del trabajo asiduo para conseguir nuevas metas didácticas, más específicamente en el campo del Computer-Assisted language Learning.

\subsection{Tipología de actividades}

Las actividades propuestas responden a diferentes tipologías formales e informales. Se trata de textos de producción escrita y oral sobre los actos lingüísticos, relacionados con la vida cotidiana. Por lo tanto, documentos adjuntos con muestras de lengua para guiar y moderar el proceso didáctico. Dichos modelos lingüísticos son necesarios para indicar los referentes lingüísticos y socioculturales de la lengua meta.

Las mini actividades son propuestas breves de producción escrita. En base a un modelo de lengua, previamente propuesto por el docente, los discentes deben producir un nuevo texto, siguiendo las indicaciones. La 
Facebook y aprendizaje informal: un nuevo planteamiento metodológico en la enseñanza de lenguas

María Angélica Giordano Paredes

función didáctica de este tipo de actividades es establecer las bases mínimas de las estructuras lingüísticas, tanto sintácticas como morfológicas, y acercar a los alumnos a la cultura de la lengua extranjera que están aprendiendo, el italiano y el español en este caso, con los principales referentes socioculturales y pragmáticos, a través de la interculturalidad que establece el contacto entre la lengua de origen y la lengua meta. El docente prepara, de la misma manera, un texto oral e invita a los miembros de la comunidad a producir sus propios audios o vídeos, según decidan en la negociación de los contenidos que se deja a libre elección de los participantes. La intención del profesor es ser un miembro más de la red para interactuar con todos sus componentes y seguir el ciclo constructivo del aprendizaje, tal y como está establecido en la taxonomía de Bloom, es decir, encaminado al desarrollo de habilidades que posibiliten la comprensión, el análisis y la aplicación, para terminar en la evaluación y la creación, siguiendo las pautas de la nueva era digital.

De esta manera, todos siguen el modelo preestablecido, pero en modo diferente, ya que, antes de escribir sus propios textos han controlado el trabajo de los compañeros.

Tabla 1

Tipología de actividades.

\begin{tabular}{|c|c|c|}
\hline Recursos & Competencias & Destrezas \\
\hline $\begin{array}{l}\text { Mini activida- Documen- } \\
\text { des sobre temas tos en for- } \\
\text { socioculturales. mato Word } \\
\text { y pdf. } \\
\text { Actividades de } \\
\text { vida cotidiana: Vídeos y au- } \\
\text { rutina, familia, dios. } \\
\text { ciudad o mon- } \\
\text { taña, gastrono- Chat de las } \\
\text { mía, vacacio- c o m u n i - } \\
\text { nes, educación. dades de } \\
\text { Actividades in- aprendizaje. } \\
\text { teractivas con } \\
\text { Gif, imágenes } \\
\text { web y audios. }\end{array}$ & 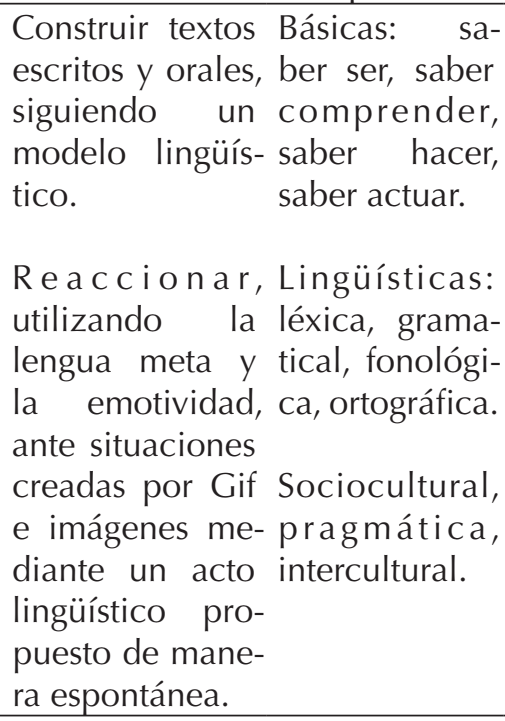 & $\begin{array}{l}\text { Com pre n - } \\
\text { sión escrita y } \\
\text { oral. } \\
\text { Producción } \\
\text { escrita y oral. } \\
\text { Interacción } \\
\text { escrita y oral. }\end{array}$ \\
\hline
\end{tabular}


Esta dinámica colaborativa acelera la adquisición de las competencias, dinamiza el modo de informar y de comunicar y facilita el aprendizaje de la lengua extranjera. Uno de los miembros de la comunidad, por ejemplo, indicó que llevaba dos años estudiando el italiano y este hecho contribuyó a que muchos de sus compañeros lo tuvieran en consideración como modelo de corrección, en caso de inseguridad; ya que la estructura de las comunidades de aprendizaje tiene que tener en cuenta los diferentes perfiles que constituyen su entramado reticular, individuos con diferentes estilos y ritmos de aprendizaje, así como con determinadas dificultades y carencias que se encuentran y entrecruzan sus conocimientos en un círculo continuo de reciprocidad y de inevitable influencia metodológica (Colombo y Varani, 2008).

En los textos orales se reproduce la lengua en modo natural, como ejemplo de la puesta en marcha del aprendizaje informal. De esta manera, Facebook contribuye a solventar, quizás, el mayor reto del e-Learning, es decir, la producción oral en el caso del aprendizaje de lenguas extranjeras. Todo esto gracias a la posibilidad de utilizar, de manera simple y práctica, una gran variedad de aplicaciones de audio y vídeo, sin límites de espacio ni incompatibilidad. Esta es una de las razones por las que Facebook se puede considerar una plataforma completa y adecuada a la enseñanza y aprendizaje, considerando que "el ecosistema Facebook influye de forma positiva en el desarrollo de la comunicación y contribuye a que los estudiantes sean conscientes de la importancia y la necesidad de la interacción como noción y parte esencial del estudio de una lengua extranjera" (Concheiro, 2016, p. 15).

\subsection{Corrección y evaluación}

La corrección es la confirmación del proceso didáctico mediante la reflexión productiva que, en este caso, es además constructiva y cooperativa; y constituye, además, una parte fundamental y necesaria de la evaluación; por lo que corregir no significa evaluar pero sin corrección no es posible la evaluación (Vázquez, 2008) por medio de la cual se accede al desarrollo de las competencias que forman parte del conjunto de conocimientos, habilidades y aptitudes, relacionadas en cualquier modo con el talento y "las inteligencias múltiples" a las que refiere Gardner (1994) y que nos permiten adaptarnos a las diferentes realidades y a cada tipo de situación de manera eficiente. Este modo de avaluar los conoci- 
Facebook y aprendizaje informal: un nuevo planteamiento metodológico en la enseñanza de lenguas

María Angélica Giordano Paredes

mientos y la realidad no estaba contemplado en la enseñanza tradicional (Cano, 2008); por lo que la nueva propuesta nos lleva al "aprendizaje significativo"; es decir, al que se adquiere mediante la interacción con el ambiente que nos rodea. El aprendizaje, por lo tanto, es el proceso que consiste en la construcción de las "representaciones personales significativas" que dan sentido a cualquier objeto, situación o representación de la realidad (Rivera, 2004).

En esta misma línea, se utilizaron las imágenes presentes entre las herramientas de las que dispone Facebook: emoticonos y stickers, en representación de los estados de ánimo que el docente quería transmitir a los alumnos: satisfacción, alegría, complicidad, sorpresa, etc. De esta manera la corrección adoptó un matiz más estimulante ya que lo que se pretendía transmitir a los discentes era que el error no es motivo de castigo sino de reflexión, verificación y reproducción a través de la interiorización y del uso apropiado de estrategias significativas. Así, se optó por seguir el modelo de corrección positiva, evidenciando los puntos débiles de manera interactiva, pero sin necesidad de señalar, particularmente, los errores.

El docente, al igual que los demás miembros de las comunidades, intervenía y respondía resaltando, en mayúsculas, las incorrecciones, con la intención de mantener la motivación y la confianza de los alumnos. De esta manera, silenciosa, se pretendía crear consciencia de los puntos débiles del aprendizaje ya que la intención era mejorar aprendiendo de todos los demás miembros de las comunidades; sin negativizar el proceso didáctico. Por esta razón, la corrección no tuvo una prioridad morfosintáctica sino constructora en su conjunto. Por lo tanto, cuando el docente corregía lo hacía con la intención de hacer reflexionar a los discentes en cada una de las competencias, creando, al mismo tiempo, a través de la coevaluación de todos los miembros, las herramientas necesarias para la autoevaluación.

En cuanto a los niveles más bajos, A1 y A2, se decidió aplicar la repetición ya que al tratarse de estudiantes de primer contacto con la lengua meta era necesario que los contenidos fueran asimilados mediante la práctica. Por lo tanto se procedió a señalizar las incorrecciones con la consiguiente aportación de la reescritura de nuevos microtextos, cuya finalidad estaba en la reflexión lingüística durante el proceso de reelaboración textual que, según Colombo y Varani (2008) consiste en un potencial cognitivo presente en todas las personas. 


\section{Análisis y resultados}

Los resultados finales del proceso de aprendizaje y enseñanza se valoraron siguiendo tres parámetros: la enseñanza a través de Facebook, el aprendizaje y la aplicación como medio de enseñanza y explotación didáctica. La intención era, en consonancia con Priscitelli, Adaime y Binder en El Proyecto Facebook (2010), proponer un nuevo espacio de construcción didáctica, abierto e innovativo, como alternativa a la metodología tradicional "una reingeniería dramática del espacio áulico (...) y un reempoderamiento de los alumnos a través de la renuncia explícita por parte de los docentes de los poderes de transmisión instituidos, partiendo de nociones estratégicas absolutamente ajenas a la tecnofilia o la tecnofobia (Priscitelli et al., 2010, p. 17). Valorando todas estas variantes se puede afirmar que en líneas generales, el $67 \%$ de los miembros de las comunidades de aprendizaje tuvieron una actitud positiva.

En cuanto a la enseñanza se puede ver a continuación, en la tabla 2, los porcentajes relacionados con la intervención docente y la propuesta de actividades o guía didáctica en el desarrollo de las comunidades de aprendizaje. No obstante la mayor parte de los miembros de la comunidad valoren muy bien y excelente la enseñanza a través de Facebook, una minoría, el $12.50 \%$ piensa que los contenidos no se entienden bien y que el docente no transmite mejor los conocimientos. En este caso se debe, principalmente, al alumnado chino cuyo perfil es más tradicional y nemotécnico; por consiguiente, fue necesario, en el caso específico de estas comunidades, hacer un trabajo paralelo de conocimiento y adaptación a la nueva metodología planteada. Se procedió, para tal fin, a la tutorización personalizada, en cuyo proceso se verificó la negación de este alumnado al trabajo colaborativo y la preponderancia de la individualidad como distintivo de dicho perfil. Sin embargo, como se puede verificar en los resultados, este porcentaje contrasta con la gran aceptación del $62.50 \%$ que considera excelente la enseñanza a través de esta red social. En cuanto a la transmisión de los conocimientos se puede apreciar una valoración muy buena del $50 \%$ y excelente del $37.50 \%$, sobre todo en las comunidades de LE constituidas por estudiantes españoles y en las de L2 compuestas por asiáticos de niveles B1 y B2 que llevaban más de dos años en España y estaban más en contacto con la cultura meta. En cambio, por lo que se refiere a los contenidos, se pueden ver más discrepancias entre un $12.50 \%$ de alumnado chino, principalmente, 
Facebook y aprendizaje informal: un nuevo planteamiento metodológico en la enseñanza de lenguas

María Angélica Giordano Paredes

de Niveles A1 y A2 que afirma que no se entienden bien, un $37.50 \%$ que sostiene que el resultado es muy bueno y el $50 \%$ que manifiesta la excelencia. Se puede decir que el resultado final es bastante positivo ya que el $100 \%$ afirma que el docente propone bien las actividades y, por lo tanto, la mayoría sostiene que la enseñanza a través de Facebook es efectiva.

Tabla 2

La enseñanza a través de Facebook

\begin{tabular}{|c|c|c|c|c|}
\hline La enseñanza a través de Facebook & Insuficiente & Bien & Muy bien & Excelente \\
\hline $\begin{array}{l}\text { El docente transmite mejor los } \\
\text { conocimientos }\end{array}$ & $12.50 \%$ & $0.00 \%$ & $50.00 \%$ & $37.50 \%$ \\
\hline Las explicaciones son más claras & $0.00 \%$ & $25.00 \%$ & $25.00 \%$ & $50.00 \%$ \\
\hline $\begin{array}{l}\text { Las actividades propuestas son } \\
\text { interesantes }\end{array}$ & $0.00 \%$ & $0.00 \%$ & $50.00 \%$ & $50.00 \%$ \\
\hline $\begin{array}{l}\text { Facebook contribuye a la motiva- } \\
\text { ción }\end{array}$ & $0.00 \%$ & $0.00 \%$ & $37.50 \%$ & $62.50 \%$ \\
\hline $\begin{array}{l}\text { Las actividades son dinámicas e } \\
\text { interactivas }\end{array}$ & $0.00 \%$ & $0.00 \%$ & $37.50 \%$ & $62.50 \%$ \\
\hline $\begin{array}{l}\text { Los contenidos son más compren- } \\
\text { sibles }\end{array}$ & $12.50 \%$ & $0.00 \%$ & $37.50 \%$ & $50.00 \%$ \\
\hline $\begin{array}{l}\text { El docente sigue mejor a los estu- } \\
\text { diantes }\end{array}$ & $0.00 \%$ & $12.50 \%$ & $37.50 \%$ & $50.00 \%$ \\
\hline $\begin{array}{l}\text { La planificación de las tareas es } \\
\text { más organizada }\end{array}$ & $0.00 \%$ & $0.00 \%$ & $37.50 \%$ & $62.50 \%$ \\
\hline $\begin{array}{l}\text { La evaluación es eficiente y com- } \\
\text { pleta }\end{array}$ & $0.00 \%$ & $12.50 \%$ & $50.00 \%$ & $37.50 \%$ \\
\hline $\begin{array}{l}\text { La propuesta de autoevaluación es } \\
\text { productiva }\end{array}$ & $0.00 \%$ & $0.00 \%$ & $50.00 \%$ & $50.00 \%$ \\
\hline El docente resuelve todas las dudas & $0.00 \%$ & $0.00 \%$ & $37.50 \%$ & $62.50 \%$ \\
\hline $\begin{array}{l}\text { El docente propone bien todas las } \\
\text { actividades }\end{array}$ & $0.00 \%$ & $0.00 \%$ & $37.50 \%$ & $62.50 \%$ \\
\hline
\end{tabular}

Al mismo tiempo se advierte un resultado motivador en cuanto a la efectividad de la organización de las tareas, la propuesta de autoevaluación y las respuestas a las dudas. La valoración también es positiva por lo que se refiere a las actividades y a la motivación, 100\%. Los demás parámetros presentan un $12.50 \%$ de discordancia entre insuficiente y bueno, sobre todo en lo relacionado con el seguimiento docente y la evaluación ya que para algunas comunidades el trabajo colaborativo los alejaba de la atención individualizada. 
En lo relativo a la valoración del aprendizaje a través de Facebook (tabla 3), un porcentaje alto de encuestados (75\%) afirma que comprende mejor las tareas; mientras el $25 \%$ restante no está muy convencido ya que considera necesaria la intervención directa del docente por no estar acostumbrado a interactuar y a aprender de los compañeros; no obstante, la valoración general sigue siendo positiva y todos coinciden en que las actividades contribuyen a estimular el aprendizaje. El 100\% confirma la eficacia del trabajo cooperativo que según Colombo y Varani (2008) conlleva a la reconstrucción de la experiencia y crea la disponibilidad de aceptar el cambio didáctico que se puede dar en todos los miembros de la comunidad mediante la observación y la reciprocidad.

Por lo que se refiere a la reflexión sobre el propio aprendizaje los resultados resultan discrepantes. No todos están de acuerdo (12\%) y piensan que no sea muy efectivo para resolver las dudas. Se trata de un perfil de alumnado que prefiere el método frontal y la guía directa del docente en la organización del aprendizaje ya que no es capaz de autogestionar los conocimientos ni de compartirlos con otros discentes. Se trata de integrantes de diferentes comunidades con mayores dificultades de aprendizaje que tuvieron, al final, un tratamiento más personalizado. Este perfil de alumnado se adapta más al aprendizaje tradicional.

La autoevaluación de los conocimientos presenta también un contraste entre el $87.50 \%$ que está convencido de la efectividad y el $12.50 \%$ que discrepa, sobre todo en el caso de alumnos que carecen de estrategias adecuadas para tal fin y de habilidades autocríticas. Sin embargo, si se considera la valoración de la mayoría se puede demostrar la eficacia del aprendizaje a través de Facebook.

Tabla 3

El aprendizaje a través de Facebook

El aprendizaje a través de Facebook Insuficiente Bien Muy bien Excelente

\begin{tabular}{|c|c|c|c|c|}
\hline $\begin{array}{l}\text { El alumno entiende mejor las acti- } \\
\text { vidades }\end{array}$ & $0.00 \%$ & $25.00 \%$ & $50.00 \%$ & $25.00 \%$ \\
\hline $\begin{array}{l}\text { El trabajo del alumno es más inte- } \\
\text { resante }\end{array}$ & $0.00 \%$ & $0.00 \%$ & $62.50 \%$ & $37.50 \%$ \\
\hline Las actividades son más motivadoras & $0,00 \%$ & $0.00 \%$ & $62.50 \%$ & $37.50 \%$ \\
\hline El aprendizaje es más fácil & $12.50 \%$ & $12.50 \%$ & $50.00 \%$ & $25.00 \%$ \\
\hline $\begin{array}{l}\text { El alumno interactúa con los com- } \\
\text { pañeros }\end{array}$ & $0.00 \%$ & $0.00 \%$ & $62.50 \%$ & $37.50 \%$ \\
\hline
\end{tabular}


Facebook y aprendizaje informal: un nuevo planteamiento metodológico en la enseñanza de lenguas

María Angélica Giordano Paredes

El aprendizaje a través de Facebook Insuficiente Bien Muy bien Excelente

\begin{tabular}{|c|c|c|c|c|}
\hline $\begin{array}{l}\text { Es mejor aprender en contacto con } \\
\text { los compañeros }\end{array}$ & $0.00 \%$ & $0.00 \%$ & $37.50 \%$ & $62.50 \%$ \\
\hline $\begin{array}{l}\text { Las imágenes facilitan la compren- } \\
\text { sión }\end{array}$ & $12.50 \%$ & $0.00 \%$ & $50.00 \%$ & $37.50 \%$ \\
\hline $\begin{array}{l}\text { Los vídeos dinamizan el proceso de } \\
\text { aprendizaje }\end{array}$ & $0.00 \%$ & $25.00 \%$ & $37.50 \%$ & $37.50 \%$ \\
\hline $\begin{array}{l}\text { El alumno aprende más de los } \\
\text { errores }\end{array}$ & $0.00 \%$ & $12.50 \%$ & $50.00 \%$ & $37.50 \%$ \\
\hline $\begin{array}{l}\text { El alumno reflexiona sobre su pro- } \\
\text { pio aprendizaje }\end{array}$ & $0.00 \%$ & $12.50 \%$ & $50.00 \%$ & $37.50 \%$ \\
\hline El alumno tiene menos dudas & $12.50 \%$ & $0.00 \%$ & $37.50 \%$ & $50.00 \%$ \\
\hline El aprendizaje es más útil y práctico & $0.00 \%$ & $12.50 \%$ & $25.00 \%$ & $62.50 \%$ \\
\hline $\begin{array}{l}\text { El alumno aprende a valorar más } \\
\text { sus conocimientos }\end{array}$ & $12.50 \%$ & $0.00 \%$ & $37.50 \%$ & $50.00 \%$ \\
\hline
\end{tabular}

En cuanto al tercer parámetro evaluado; es decir, Facebook como recurso de aprendizaje, los datos confirman el éxito de la red social. El $100 \%$ de los estudiantes manifiestan estar satisfechos con la experiencia didáctica en las comunidades de aprendizaje.

Los discentes aprendieron, además de los contenidos y las estructuras de la lengua meta, los principales referentes culturales y su aplicación a través de los actos de habla que se Ilevaron a cabo mediante el desarroIlo de la competencia pragmática, facilitando el aprendizaje de la lengua meta y potenciando tanto la expresión como la comprensión orales, gracias al contacto directo o indirecto con los compañeros de grupo y al uso de las herramientas y recursos tecnológicos que hacían posible la reproducción de textos orales, necesarios e imprescindibles para la corrección, el alcance y la pronunciación. Además, a través de las salas de chat, y del uso de las herramientas disponibles como sticker, gif y audios, los discentes pudieron crear textos orales y reaccionar a las situaciones creadas, simulando y al mismo tiempo formando parte de una conversación real, entre los miembros de la comunidad o de otras comunidades, de manera interactiva y constructiva. En este sentido, el proceso experimental compartió con el trabajo de Pilar Concheiro (2016) la posibilidad de constituir el espacio digital como área de aprendizaje colaborativo de las lenguas extranjeras, de manera autónoma y significativa, ya que Facebook ofrece la posibilidad de adentrar el aula en la vida real y vice- 
versa. Así que, al contrastar la investigación con otros estudios empíricos no se puede más que confirmar la misma finalidad, encaminada a un inminente cambio didáctico.

\section{Conclusiones}

Los resultados de tres años de experimentación lingüística ponen en evidencia la eficacia de Facebook en el proceso de enseñanza y aprendizaje. Así lo reflejan los cuestionarios aplicados al proceso didáctico; aunque con algunas variaciones, especialmente en el nivel B1, los resultados globales no han sufrido muchas alteraciones. Eso indica que la enseñanza de lenguas necesita adaptarse a las tecnologías más avanzadas para conseguir, así, acercarse a los intereses de los discentes, con una dinámica ligera e informal que garantice la capacidad de comunicar usando los códigos de la lengua meta, respetando el contexto y el modo de ser y de hacer de la respectiva comunidad lingüística, dentro de los límites pragmáticos y socioculturales del saber hacer y saber comportarse.

A lo largo del proceso experimental se verificó un acercamiento tanto a la lengua como a la cultura meta a través de la puesta en práctica de actividades contextualizadas que tenían como finalidad desarrollar las competencias pragmática y sociolingüística y al mismo tiempo, distinguir, las diferencias socioculturales entre ambas sociedades; demostrando, así, la necesidad de integrar estas competencias a las lingüísticas.

Aunque el proceso respondió positivamente tanto a las hipótesis como a los objetivos propuestos, un porcentaje reducido de estudiantes se manifestó a favor del aprendizaje tradicional, por lo que la secuencia didáctica diseñada requirió un cierto esfuerzo. Fue el caso de algunos alumnos chinos muy sumergidos en metodologías nemotécnicas y para quienes resultó difícil asimilar el aprendizaje fuera de los parámetros formal y frontal.

La mayoría de los discentes respondió positivamente a la experimentación gracias a la organización de los grupos y a la tipología de actividades que les facilitó la interiorización de los contenidos, por lo que al final consiguieron valorar este tipo de aprendizaje; además del acercamiento a los compañeros y a la autoconfianza a través de la colaboración y el uso de herramientas y dinámicas colectivas.

Al final del proceso experimental se pudo demostrar, no obstante la 
Facebook y aprendizaje informal: un nuevo planteamiento metodológico en la enseñanza de lenguas

María Angélica Giordano Paredes

tendencia al trabajo individual, que el aprendizaje informal es productivo y muchos entendieron que en realidad todo el proceso planteado en Facebook había enriquecido, ampliamente, sus expectativas lingüísticas. Sin embargo, no siempre fue fácil introducir nuevas variantes en los modos tradicionales de aprendizaje y, sobre todo, acercar a los estudiantes a ver el proceso didáctico como una red de intercambio de conocimientos y de socialización.

Para concluir, se puede afirmar que la experimentación fue bastante compleja y variable ya que durante el proceso, tanto el docente como los aprendientes, sostuvieron un trabajo diversificado e intenso de descubrimiento, a través de la experiencia y de las múltiples formas de explotación glotodidáctica de los contenidos, hasta llegar a la convicción de que el proceso puede ser ilimitado debido a la flexibilidad de la plataforma. Los resultados, por lo tanto, apuntan a la posibilidad de incluir Facebook, incluso, en la enseñanza formal como punto de apoyo para la propuesta de nuevas metodologías de aprendizaje ya que, según Baran (2010), las nuevas generaciones lo englobarán con mayor facilidad.

\section{Referencias}

Álvarez, A. (2014). Actitudes y valoración en el uso de una red social para el aprendizaje. Revista de Comunicación Vivat Academia, 17(128), 92-106. https://doi.org/10.15178/ va.2014.128.92-106.

Baran, B. (2010). Facebook as a formal instructional environment. British Journal of Educational Technology, 41(6), 146-149. https://doi.org/10.1111/j.14678535.2010.01115.x.

Bartolotta, S., Giordano Paredes, M. A. y Moreno Celeghin, M. G. (2018). Web 2.0 y aprendizaje cooperativo: una propuesta de la Universidad Nacional de Educación a Distancia para la enseñanza de la lengua italiana. En O. Buzón García (Coord.), Nuevas pedagogías con tecnologías emergentes (pp. 67-83). Madrid: Dykinson S.L.

Cano García, M. E. (2008). La evaluación por competencias en la educación superior. Revista de Currículum y Formación de Profesorado, 12(3), 1-16. Recuperado de https://recyt.fecyt.es/index.php/profesorado/article/view/42469/24384.

Coinu, M. (2006). Le teorie del apprendimento. Dispensa Didattica per il Corso di Progettazione Didattica per la Formazione a Distanza. Roma: Università La Sapienza di Roma.

Colombo, M. y Varani, A. (2008). Costruttivismo e riflessività. La formazione alla pratica di insegnamento. Bergamo: Edizioni Junior.

Concheiro Coello, P. (2016). Facebook como espacio de aprendizaje de ELE en el contexto islandés y su efecto en el proceso de lectoescritura. Redele Revista Electrónica 
Facebook y aprendizaje informal: un nuevo planteamiento metodológico en la enseñanza de lenguas María Angélica Giordano Paredes

de Didáctica del Español Lengua Extranjera, (28), 1-29. Recuperado de https://sede. educacion.gob.es/publiventa/redele-n-28-revista-electronica-de-didactica-espanolcomo-lengua-extranjera/ensenanza-lengua-espanola/21627.

Fewkes, A. y Mccabe, M. (2012). Facebook: Learning tool or distraction? Journal of Digital Learning in Teacher Education, 28(3), 92-98. https://doi.org/10.1080/21532974 .2012.10784686.

Garayzábal Heinze, E. y Codesido García, A. I. (2015). Fundamentos de Psicología lingüística. Madrid: Editorial Síntesis.

Gardner, H. (1994). Intelligenze multiple. Milano: Anabasi.

Parra Castrillón, E. (2010). Las redes sociales de Internet: también dentro de los hábitos de los estudiantes universitarios. Tendencias, 11(2), 193-207. Recuperado de https:// revistas.udenar.edu.co/index.php/rtend/article/view/589.

Pepe, D. (1997). La psicologia di Piaget nella cultura e nella società italiane. Milano: FrancoAngeli.

Piaget, J. (1976). Il linguaggio e il pensiero del fanciullo. Firenze: Giunti Barbera.

Priscitelli, A., Adaime, I. y Binder, I. (Comps.) (2010). El Proyecto Facebook y la pos universidad. Sistemas operativos sociales y entornos abiertos de aprendizaje. Madrid: Ariel y Fundación Telefónica.

Rivoltella, P. C. (2003). Costruttivismo e pragmatica della comunicazione on line. Società e didattica in Internet. Trento: Erickson.

Sancassani, S., Brambilla, F., Marenghi, P. y Menon, S. (2011). E-Collaboration II senso della Rete. Metodi e strumenti per la collaborazione online. Milano: Apogeo.

Santalucia, D. (2015). Competenza digitale e glottotecnologie per l'insegnante di italiano L2/LS. Italiano LinguaDue, 7(1), 157-183. https://doi.org/10.13130/2037-3597/5040.

Trinchero, R. (2014). Valutare l'apprendimento nell'e-learning. Dalle abilità alle competenze. Trento: Erickson.

Trujillo Torres, J. M., Cáceres Reche, M. Pilar, Hinojo Lucena, F. J. y Aznar Díaz, I. (2011). Aprendizaje cooperativo en entornos virtuales. El proyecto Redes Educativas y Organizativas Interuniversitarias. Educar, 47(1), 95-119. Recuperado de https://ddd.uab. cat/pub/educar/0211819Xv47n1/0211819Xv47n1p95.pdf.

Vázquez Cano, E., Sevillano García, M. L. (2011). Educadores en red. Elaboración y edición de materiales audiovisuales para la enseñanza. Madrid: Ediciones Académicas (UNED).

Vázquez, G. (2008). De la corrección de errores a la evaluación de las competencias: impacto de la evaluación sobre las personas y la sociedad. En XVIII Congreso Internacional de la Asociación para la Enseñanza del Español como Lengua Extranjera (ASELE). (pp. 45-55). Alicante: Centro Virtual Cervantes. En https://cvc.cervantes.es/ ensenanza/biblioteca_ele/asele/pdf/18/18_0045.pdf.

Vygotskji, L. (1980). I/ processo cognitivo. Torino: Boringheri.

Wenger, E. (1998). Communities of practise. Learning meaning and identity. Cambridge: University Press.

Wong, L. H., Chai, C. S. y Aw, G. P. (2017). Seamless Language Learning: Second Language Learning with Social Media. Comunicar, 25(50), 9-20. https://doi.org/10.3916/ C50-2017-01. 
Facebook y aprendizaje informal: un nuevo planteamiento metodológico en la enseñanza de lenguas

María Angélica Giordano Paredes

Zhang, D, Zhao, J. L., Zhou, L. y Nunamaker, J. F. (2004). Can e-learning replace classroom learning? Communications of the ACM, 47(5), 75-79. https://doi. org/10.1145/986213.986216. 